\title{
Las teorías postdisciplinarias y el desafío de describir una nueva tecnología del poder
}

Jonathan Enrique Prueger ${ }^{1}$

Recibido: 13/07/2020; Aceptado: 20/10/2020

Cómo citar: Prueger, J. E. (2020) Las teorías postdisciplinarias y el desafío de describir una nueva tecnología del poder, Revista Hipertextos, 8 (14), pp. 73-90. DOI: https://doi.org/10.24215/23143924e020

Resumen. Situándose en el marco de las teorías del poder foucaultianas/postfoucaultianas, y asumiendo el desafío de la continua reactualización de sus herramientas analíticas, el objetivo del presente artículo es aportar a la caracterización de lo que implicaría una nueva tecnología del poder (psicopolítica/noopolítica). La misma ha tendido a ocupar un lugar de centralidad ascendente hasta el comienzo de la tercera década del s. XXI, donde la pandemia del COVID-19 vuelve a dar cierto protagonismo a los dispositivos y técnicas de la biopolitica. Antes de emprender el estudio en torno a las transformaciones del poder en curso -los nuevos imbricamientos entre las distintas tecnologías de poder- es necesario arrojar algunas luces nuevas en torno a la caracterización de lo que representaría el núcleo conceptual de una caja de herramientas mixta para las analíticas del poder del hoy. La conjunción de Lazzarato y Han (Cerruti, 2017) nos permite integrar los registros del ciberespacio, los signos, la memoria, con aquellos que atañen a una perspectiva centrada en la psique, el inconsciente y las políticas del deseo. Previo a esto, insistiremos en el repaso pertinente del marco teórico común (postdisciplinario) que brindan Foucault y Deleuze.

Palabras clave: postidisciplinario, biopolítica, control, psicopolítica, noopolítica.

\section{Postdisciplinary theories and the challenge of describing a new technology of power}

Abstract. Placing itself within the framework of foucaultian/postfoucaultian theories of power, and assuming the challenge of contributing to the continuous updating of their respective analytical tools, the objective of this article is to contribute to the characterization of a new technology of power (psicopolítics/noopolítics). It has tended to occupy a place of ascending centrality until the beginning of the third decade of the s. XXI, where the COVID-19 pandemic once again gives a certain prominence to the devices and techniques of biopolitics. Before undertaking the study of the ongoing transformations of power -the new overlaps between the different technologies of power- it is necessary to shed some new light on the characterization of what the conceptual core of a mixed toolbox would represent for the analytics of the power of today. The conjunction of Lazzarato and Han (Cerruti, 2017) allows us to integrate the records of cyberspace, signs, memory, with those that concern a perspective centered on the psyche, the unconscious and the politics of desire. Prior to this, we will insist on the pertinent review of the common (postdisciplinary) theoretical framework provided by Foucault and Deleuze.

\footnotetext{
${ }^{1}$ Lic. en Sociología de la Facultad de Humanidades y Cs. de la Educación de la Universidad Nacional de La Plata. Contacto: ejprueger@gmail.com
} 
Keywords: postdisciplinary, biopolitics, control, psychopolitics, noopolitics.

\section{Teorias pósdisciplinares e o desafio de descrever uma nova tecnologia de poder}

Resumo. Inserindo-se no quadro das teorias foucaultianas/pós-foucaultianas do poder, e assumindo o desafio de contribuir para a atualização contínua das respetivas ferramentas analíticas, o objetivo deste artigo é contribuir para a caracterização do uma nova tecnologia do poder (psicopolitico/noopolítica). Tende a ocupar um lugar de centralidade ascendente até o início da terceira década do s. XXI, onde a pandemia COVID19 volta a conferir certo destaque aos dispositivos e técnicas da biopolítica. Antes de empreender o estudo das transformações em curso de poder -as novas sobreposições entre as diferentes tecnologias de poderé necessário lançar uma nova luz sobre a caracterização do que representaria o núcleo conceitual de uma caixa de ferramentas mista. a análise do poder de hoje. A conjunção de Lazzarato e Han (Cerruti, 2017) nos permite integrar os registros do ciberespaço, dos signos, da memória, com aqueles que dizem respeito a uma perspectiva centrada no psiquismo, no inconsciente e na política do desejo. Antes disso, insistiremos na revisão pertinente do quadro teórico comum (pós-disciplinar) fornecido por Foucault e Deleuze.

Palavras-chave: pós-disciplinar, biopolítica, controle, psicopolítica, noopolítica. 


\section{Algunas conjunciones teóricas para las analíticas del poder de hoy}

En términos generales, Foucault (2008) entiende por tecnología de poder un conjunto híbrido de instrumentos, saberes, sistemas de juicio y procedimientos orientados prácticamente en función de determinados objetivos. Una aproximación integral a su fructífera obra permite percibir cómo dicho autor no se ha cansado de actualizar y reactualizar tanto elementos como la integralidad de las cajas de herramientas por él creadas. Sin embargo, frente a las transformaciones paradigmáticas de las dinámicas del poder -que exigen la continúa reactualización de las herramientas analíticas a utilizar- Foucault $(1977,1998,2006)$ llama la atención sobre algunas constantes singulares de la historia. Da cuenta de cómo las endemias, epidemias y pandemias suelen constituir instancias donde se amplían, ensayan y generalizan determinadas técnicas y dispositivos del poder. El abordaje político de la lepra (en la Europa medieval) expresó la generalización de un modelo soberano de exclusión radical. El abordaje de la peste (durante el s. XVIII) constituyó una instancia donde se pusieron a prueba formas de segregar incluyendo, desde las cuales se implementaron las tecnologías de la anatomopolítica disciplinaria de los cuerpos individuales. Tanto la gripe española como los campos de concentración nazis y los gulags (de mediados del s. XX), constituyeron instancias donde se pusieron a prueba tecnologías de la biopolítica regulatoria de las poblaciones. En lo que respecta al sida, Preciado (2020) indica que emerge en plena crisis del heteronormativismo de la sociedad neoliberal del último cuarto del s. XX, donde la homosexualidad comenzaba a dejar de ser considerada una enfermedad psiquiátrica, reactualizando un conjunto de controles sobre los cuerpos y particularmente sobre la sexualidad.

Es posible identificar momentos en la historia donde a cada nueva tecnología del poder, o a cada nueva rearticulación de las tecnologías del poder, le corresponde una respectiva instancia de pruebas y ensayos. Los desafíos que enfrentan y enfrentaran nuestras sociedades en el marco de la transición pandemia/postpandemia de COVID-19 vuelve a poner sobre la mesa la necesidad de revisar, actualizar y disponer de las analíticas del poder que podrían aportar a desentrañar el carácter de las transformaciones sociales en curso y proveer insumos para la política pública en sentido amplio ${ }^{2}$.

En Seguridad, Territorio, Población (2006 [1978]), Foucault expuso su conceptualización de las sociedades de seguridad como nueva caja de herramientas para desentrañar las dinámicas del poder, identificando la caducidad de la pertinencia del modelo teórico de las sociedades disciplinarias a la hora de analizar las emergentes sociedades neoliberales del último cuarto del s. XX. Una década más tarde, Deleuze $(1987,1989)$ vuelve a anunciar dicha caducidad y encumbra su propuesta teórica de las sociedades de control, donde la dimensión de la información y las TIC's (Tecnologías de Información y la Comunicación) detentan un lugar de mayor centralidad. Lo más novedoso

\footnotetext{
${ }^{2}$ Estoy proyectando, bajo la dirección de Pablo Rodríguez (IIGG-CONICET), un estudio que parte de la hipótesis de que las distintas transiciones del escenario pandemia/postpandemia de COVID-19 podrían constituir un nuevo "laboratorio de ensayos" donde se pongan a prueba nuevas técnicas y dispositivos del poder, los cuales podrían implicar nuevos modos en que se expresen, articulen y solapen exclusión radical, anatomopolítica, biopolitica y psicopolitica/noopolítica. Para ello nos valdremos de las herramientas de las teorías del poder focualtianas/postfoucualtianas en articulación con ciertas perspectivas situadas (perspectivas decoloniales y teoría de la dependencia, fundamentalmente) en dirección a analizar las transformaciones del poder en curso en Argentina; país periférico, dependiente y sujeto históricamente a las distintas formas de colonialidad. De esta manera, tambien podremos aportar a los avances que ya se vienen realizando en el registro de dicha articulación teórica. Particularmente destacamos las producciones de Grosfoguel (2012), Restrepo (2004), Castro-Gómez (2007 y 2010), Walsh (2005), Díaz (2000) y Couldry y Mejías (2019).
} 
de dicho énfasis reside en el recurso a la teoría de la transducción de Simondon (2014). Allí, los conceptos de comunicación e información se revelan como portadores de un potencial epistémico superador frente a las premisas que fundan las matrices epistemológicas de la modernidad (Rodríguez, 2019). Tanto la propuesta securitaria foucaultiana como la del control deleuziano han logrado consolidarse como base teórica común para un amplio registro de Las teorías del poder postdisciplinario (Prueger, 2020). En definitiva, sociedades de control (Deleuze, 1991), sociedad del riesgo (Beck,1998), sociedad de la información (Masuda, 1984), sociedad red (Castells, 2000), sociedad de los metadatos (Pasquinelli, 2011), sociedad del rendimiento (Han, 2012) se encuentran entre las más destacadas propuestas teóricas que -coincidiendo en las limitaciones del modelo teórico foucaultiano de las sociedades disciplinarias y discutiendo directa o indirectamente con las sociedades de seguridad (Foucault, 2006) - buscan desarrollar una nueva analítica del poder para nuestras sociedades neoliberales contemporáneas.

Como podemos ver, las teorías del poder foucaultianas/postfoucaultianas continúan integrando propuestas teóricas emergentes, sumado a un acervo de artículos que realizan continuas sistematizaciones. Recuperar dicho registro teórico constituye la oportunidad de conjugar e interrelacionar creativamente las herramientas que nos brindan los distintos marcos analíticos que comprenden en su interior. Nos serviremos de los avances bibliográficos ya realizados hasta el momento en esa dirección (Rodríguez, 2008; Cruz Ortiz, 2016; Gendler, 2017; Cerruti, 2017; entre otros). Sin embargo, falta dar algunos pasos más: llevar a delante algunas decisiones teóricas claves que nos permitan configurar una caja de herramientas mixta para las analíticas del poder de hoy.

El objetivo del presente artículo es aportar a la caracterización de lo que implicaría una nueva tecnología del poder psicopolítica/noopolítica, la cual ha tendido a ocupar un lugar de mayor centralidad hasta el comienzo de la tercera década del s. XXI, donde la pandemia del COVID-19 vuelve a dar cierto protagonismo a los dispositivos y técnicas de la biopolítica. Antes de emprender el estudio en torno a las transformaciones del poder en curso, los nuevos imbricamientos entre las distintas tecnologías de poder, es necesario arrojar algunas luces nuevas en torno a la caracterización de lo que representaría cierto núcleo conceptual de nuestra caja de herramientas mixta: las tecnologías del poder psicopoliticas/noopoliticas. Previo a esto, insistiremos en el repaso pertinente del marco teórico común que brindan Foucault y Deleuze.

\section{Las revoluciones de las tecnologías del poder}

Foucault identifica dos revoluciones de las tecnologías del poder. La primera fue el descubrimiento de la disciplina en los siglos XVII y XVIII (Foucault, 2002a): las técnicas de distribución, organización, supervisión y adiestramiento de los cuerpos en términos individuales. Constituye el registro de aquello que Foucault define como la anatomopolítica: la tecnología del poder "se dirige a los individuos hasta anatomizarlos" (Foucault, 1999: 245). El nacimiento de la anatomopolítica se encuentra estrechamente vinculado al surgimiento de las instituciones disciplinarias. De la mano con la consolidación de la modernidad capitalista, un conjunto de instituciones fue tomando un papel cada vez más importante: escuelas, talleres, fábricas, hospicios, hospitales y cárceles, entre las principales. Las mismas son caracterizadas como espacios de encierro donde los cuerpos son acostumbrados a determinadas conductas, actitudes y predisposiciones. La segunda revolución de las tecnologías del poder se desarrolla durante el s. XVIII, y es la cual da 
origen a una biopolitica en dirección a la regulación del "cuerpo social general", es decir: en tanto “conjunto de seres vivos constituidos como población” (Foucault, 1999: 209). Allí se desarrollan los dispositivos de regulación y moldeamiento de la natalidad, la longevidad, la salud, la higiene, la "raza", que se encuentran entre las principales incumbencias de la regulación política de las poblaciones. Hablamos de un biopoder planificado que se ejerce en términos positivos sobre la vida, que procura "administrarla, aumentarla, multiplicarla, ejercer sobre ella controles precisos y regulaciones generales" (Foucault, 1998: 82).

En las dos revoluciones de las tecnologías del poder, se expresa lo que Foucault (2007) describe como una avanzada hacia la configuración de los cuerpos individuales dóciles (anatomopolitica) y un cuerpo social 'saludable' (biopolitica). Ambas revoluciones se inscriben en el registro del biopoder. Sin embargo, en el último tramo de su vida Foucault identifica una nueva forma de violencia autodirigida; la cual ubica por fuera del registro de las tecnologías del poder. Con tecnologías del yo intento describir un conjunto de dispositivos y técnicas que "permiten a los individuos efectuar, por cuenta propia o con la ayuda de otros, cierto número de operaciones sobre su cuerpo y su alma, pensamientos, conducta, o cualquier forma de ser, obteniendo así una transformación de sí mismos con el fin de alcanzar cierto estado de felicidad, pureza, sabiduría o inmortalidad" (Foucault, 2008:48).

Las tecnologías del yo constituyen el aporte que realiza Foucault -en el último tramo de su vidaen torno ciertas transformaciones en las dinámicas del poder que comenzaban a desarrollarse pero que aún no llegaban a consolidarse. Más tarde, otros autores continuando el legado foucaultiano describirán aquello que representaría una nueva tecnología del poder en dirección al intelecto (Lazzarato, 2006) o la psique (Han, 2018a); la cual comenzaba a hacerse cada vez más presente de la mano del desarrollo y generalización de las TIC's en nuestras sociedades neoliberales contemporáneas.

\section{Sociedades securitarias y sociedades de control}

Según Foucault, el poder disciplinario se caracteriza por una clara tendencia centrípeta. La disciplina concentra, segmenta y delimita espacios cerrados (instituciones disciplinarias) donde el poder se desenvuelve plenamente (Foucault, 2006: 66). En cambio, el poder securitario se expresa de manera predominantemente centrífuga, es decir: se amplían espacios y se anexan elementos en dirección al "desarrollo de circuitos cada vez más grandes" (p. 67). La disciplina tiende a reglamentar normativamente lo más posible. Ni el más mínimo detalle debe escapar al moldeamiento disciplinario, nada debe estar abandonado a su suerte y cada pequeña infracción debe ser señalada y corregida. Ante una evidente emergencia de discursos y políticas neoliberales ${ }^{3}$, Foucault plantea que en las sociedades de securitarias vuelve a cobrar actualidad la propuesta de intervención política en lo social de los fisiócratas liberales del s. XVIII. Partiendo de un supuesto que equipara lo social con lo natural, los fisiócratas plantean que, más que intervenir prescriptivamente, hay que dejar que lo social se desenvuelva 'naturalmente'. En todo

\footnotetext{
${ }^{3}$ La reactualización del proyecto liberal en su faceta "neo" vino de la mano con la contrarrevolución conservadora en la década de 1980 en el polo angloamericano, de la mano de Thatcher en Reino Unido y Reagan en Estados Unidos. En términos de programa económico se alinearon a los planteos de la Escuela neoclásica y en términos político-sociales sosteniendo un claro perfil neoconservador. Dicho programa neoconservador se montó en la creciente transnacionalización del capital, la cual -a su vez- se apalancó en la Tercera Revolución Industrial y, particularmente, en el auge de las Tecnologías de la Información y la Comunicación (TIC’s).
} 
caso procurar establecer regulaciones generales que contribuyan a mantener las condiciones generales del ordenamiento social. La célebre frase "dejen hacer, dejen pasar, el mundo va solo", acuñada por Vicent de Gournay a mediados del s. XVIII, es la que mejor expresa esta inclinación en favor de cierta 'autorregulación' de la sociedad capitalista por parte del pensamiento fisiocrático. Los dispositivos de seguridad integran, como una parte intrínseca a su despliegue, márgenes de permisividad desde donde también se afirma el poder. Poder que -en lugar de pretender reglamentar, verificar y moldearlo todo- configura espacios de libertad; los cuales contribuyen a cierta autonomización de la sujeción a la dominación por parte de la sociedad civil.

De esta manera, encontramos en el Foucault de las sociedades securitarias, la noción de que la libertad constituye una dimensión fundamental en la cual se afirma el poder postdisciplinario (Foucault, 2006: 71). Así es que se van consolidando gubernamentalidades donde se toma "en cuenta en primer lugar la libertad de los hombres, lo que éstos quieren hacer, lo que están interesados en hacer, lo que piensan hacer" (Ibíd.). La gubernamentalidad postdisciplinaria, que se proyecta hacia los espacios abiertos, se expresa fundamentalmente en las grandes ciudades. Los dispositivos de seguridad permiten circular, que las cosas se muevan de un lugar a otro sin detenerse, pero de una determinada manera donde se elimina toda posibilidad de puesta en jaque del ordenamiento social general; se puede condicionar "sin que la gente lo advierta demasiado" o permanezca lo más "inconsciente de lo que se la hace hacer"4 (p. 132).

Aquel pasaje de un predominio de una dinámica centrípeta a otra centrífuga, Deleuze la identifica no sólo en relación a la espacialidad, sino también a la temporalidad. De esta manera, la ruptura implicaría el desplazamiento de una disciplina de espacios reducidos y tiempos delimitados (aunque constantes) a un control de espacios abiertos y temporalidades completas (aunque fragmentadas). A modo de ejemplo de esto último, Deleuze expone el auge de las propuestas de formación permanente en el área educativa ${ }^{5}$ (Deleuze, 1991: 2). Por otro lado, aquella búsqueda de un poder que pretender condicionar "sin que la gente lo advierta demasiado", que señala Foucault, encuentra correspondencia en la identificación de Deleuze del marketing como principal modelo de influencia y persuasión en las sociedades de control. Dicho autor da cuenta de las nuevas características que va asumiendo un capitalismo donde la información, las dimensiones cognitivas y afectivo-emocionales ocupan un lugar cada vez más importante.

Deleuze describe un poder que tiende continuamente hacia la diferenciación, no sólo en términos interindividuales sino también en términos intraindividuales (dividuación). De esta manera, introduce los aportes de un filósofo fundamental para estos tiempos que corren, el cual hasta ahora recuperamos superficialmente: Gilbert Simondon. Dicho autor, a fines de la década de los 50', propuso una ruptura en las formas de concebir los procesos de continuidad y

\footnotetext{
4 A riesgo de pecar de ecléctico, quisiera traer a colación los aportes de un autor marxista que también supo reflexionar en torno a las trasformaciones del poder. Cuando Gramsci (1990) analiza comparativamente "el Estado en Oriente y el Estado en Occidente", logra dar cuenta de un fenómeno que al parecer no ha dejado de profundizarse hasta nuestros días. Esto es: cómo la reproducción en el tiempo del modo de producción capitalista recae cada vez menos en la monopolización de la coacción física, y la puesta en ejercicio de tal capacidad, y se apoya cada vez más en la producción de consenso - sea este activo o pasivo- en torno a la legitimidad de los fundamentos ideológico-culturales y materiales de su dominación sobre el todo social. Es esta tendencia la que también podemos encontrar en lo que describiera Foucault como cierta transición de las sociedades de soberanía a las sociedades disciplinarias, así como también en lo que implicaría la transición de estas últimas a las postdisciplinarias (en las sociedades securitarias de Foucault o, como veremos a continuación, en la propuesta de las sociedades de control de Deleuze).

5 En términos más contemporáneos, bien podríamos hablar aquí de ciertos modos de habitar el tiempo que promueven las TIC's y las RR.SS. (redes sociales digitales) en la actualidad.
} 
discontinuidad en lo físico, en lo biológico, en lo social y en lo psicológico. Simondon (2014) logra desfetichizar los supuestos aristotélicos de la episteme moderna occidental, la cual tiende a concebir aquello que define como 'substancia' en términos permanentes, absolutos y estáticos. Con su teoría de la transducción, propone un modelo teórico que permite pensar la complejidad de los procesos de individuación y transindividuación tanto en lo físico, lo biológico, como en la psicogénesis o lo social (transindividual).

Para Simondon la idea de 'moldear', sustentada en el hilemorfismo aristotélico ${ }^{6}$, resulta pertinente reemplazarla por la idea de 'modular'. He aquí el concepto que incluye Deleuze (1991) en Posdata sobre las sociedades de control: "los controles son modulaciones" (p. 2). Analizar la realidad social en términos de procesos que 'moldean' (subjetividades, cuerpos) constituye un resabio del modelo teórico de las sociedades disciplinarias. Concebir la dinámica de lo social en términos de 'modulaciones' pareciera resultar más pertinente en tiempos de ciberespacio y control (Rodríguez, 2015a: 374). La modulación detenta mayor capacidad explicativa a la hora de analizar los dispositivos del control (o securitarios en Foucault), los cuales establecen regulaciones generales: se apoyan en ciertos márgenes de libertad de los individuos y en procesos del poder más fluctuantes que estáticos. No es que antes no existían las modulaciones y ahora sí, siempre las hubo (Gendler, 2017). El problema es que nunca antes, de la mano con el desarrollo y generalización de las TIC's en las sociedades neoliberales contemporáneas, las técnicas y dispositivos del poder habían estado tan fructíferamente orientados hacia el desmembramiento de la subjetividad e intersubjetividad -hasta en lo más milimétrico- en flujos de información.

Mientras los dispositivos disciplinarios pretenden el moldeamiento uniforme y absoluto del individuo, los dispositivos del control tienden a una fragmentación de su integridad. Aquí es donde entra a colación la noción de lo "dividual" que -evidentemente- Deleuze (1991: 4) recupera también de Simondon. Lo dividual refiere a la posibilidad de dividir infinitamente una interioridad en términos de información ${ }^{8}$ (Simondon, 2014; Muir, 2012). Dicha faceta toma una relevancia aún mayor si desplazamos temporalmente esto que destaca la recuperación deleuziana de Simondon a la luz de las técnicas propias del Big Data y su automatizado relevamiento de información de los usuarios. Vale la pena recuperar la noción de gubernamentalidad algorítmica de Rouvroy y Berns (2016), la cual refiere a: "un cierto tipo de racionalidad (a)normativa o (a)política que reposa sobre la recolección, agrupación y análisis automatizado de datos en cantidad masiva de modo de modelizar, anticipar y afectar por adelantado los comportamientos posibles" (p. 96).

Lo dividual también refiere a cierto proceso de fragmentación de la subjetividad, de un sujeto contemporáneo que pareciera extraviarse en términos identitarios frente a los dispositivos del

\footnotetext{
${ }^{6} \mathrm{El}$ hilemorfismo aristotélico constituye la teoría filosófica que plantea que los cuerpos físicos están constituidos por dos principios elementales diferenciados: la materia y la forma.

7 El ciberespacio constituye el conjunto de espacialidades digitales creadas mediante instrumentos cibernéticos. La cibernética es el estudio interdisciplinario de las estructuras de los sistemas reguladores. Es decir, el estudio de los flujos de energía estrechamente vinculados a la teoría de control (estudio de los comportamientos dinámicos) y a la teoría de sistemas (estudio las dinámicas de los sistemas en general). Siguiendo a Barrios (2019): "El ciberespacio es un lugar creado a través de la interconexión de sistemas de ordenadores mediante internet. Es un espacio global dentro del entorno del Sistema Mundo que consiste en una red interdependiente de infraestructura de información, incluyendo internet, redes de telecomunicaciones, sistemas informáticos, procesadores y controladores"

${ }^{8}$ Las modulaciones que caracterizan la dinámica de los dispositivos del control sustentan su adaptabilidad y fluidez en esta descomposición del mundo en datos e información. Gendler afirma que en las sociedades de control "importa menos el individuo como sujeto/todo en sí mismo que las cifras, datos e informaciones que se desprenden de ese individuo" (Gendler, 2017: 63).
} 
control. En esta segunda faceta de lo dividual, no podemos dejar de mencionar los aportes de Sennett (2007) en relación a la descripción de cierta "corrosión del carácter" en las sociedades de "nuevo capitalismo" (postfordistas). El sujeto de las sociedades postfordistas, ante la imposibilidad de tener un trabajo estable, ve desintegrar su experiencia y trayectoria biográfica en una sumatoria de fragmentos diseminados (p. 70). En una línea similar, Agamben (2014) realiza su propuesta de lo que serían los procesos de "desubjetivación". Los mismos contribuyen a configurar un sujeto con dificultad de afirmarse, absorbido por la diversidad del consumo; el cual encuentra su máxima expresión en el espectador cotidiano de producciones audiovisuales (zappeur) (p. 24). Fragmentación de la subjetividad, corrosión del carácter, desubjetivación o dividualización, conceptualizaciones distintas de un fenómeno similar que encuentra anclaje en lo que identifican tanto el Foucault de las sociedades securitarias como Deleuze: una tendencia centrífuga como signo propio de la dinámica del poder postdisciplinario; lo que se expresa en el extravío subjetivo en la exterioridad por parte de los sujetos de las sociedades neoliberales contemporáneas.

Recuperando los aportes de Foucault y Deleuze, podemos dar cuenta de cómo un nuevo modelo teórico comenzaba a tomar cada vez más forma. Sin embargo, aquellos autores reflexionaron y escribieron partiendo de las sociedades neoliberales de fines de s. XX. Como vienen manifestando distintas producciones en este campo de estudio, las transformaciones tecnocientíficas y tecnocomunicacionales - con sus respectivas generalizaciones en las sociedades neoliberales de s. XXI- fueron contribuyendo a la inminente consolidación de una nueva tecnología del poder.

\section{Una nueva revolución de las tecnologías del poder: Lazzarato y Han}

En lo que hace a esta conjunción analítica, es necesario comenzar diciendo que el presente trabajo viene a sumar, complementar e integrar los aportes que oriento el trabajo de Cerruti (2017): De la biopolitica a la psicopolitica: comunicación, poder y subjetividad a partir de Michael Foucault. Bajo los registros de estudio que integran biopolítica-psicopolítica y biopolitica-noopolítica, también es posible encontrar todo un campo de análisis en continuo crecimiento (Rodriguez, 2010; Velásquez, 2012; Cruz Ortiz, 2016; Gendler, 2017; Mallamaci, 2017; Galparsoro, 2017; entre otros). Lo pendiente es asumir el desafío creativo de arriesgar la formulación y puesta en ejercicio de una caja de herramientas mixta para analizar las dinámicas del poder de un hoy en pleno movimiento y transformación.

Al interior del espectro postdisciplinario, encontramos dos propuestas destacables que identifican una ruptura en lo que hace a la centralidad de las tecnologías del biopoder. De la mano con el desarrollo y generalización de las TIC's, una nueva modalidad del poder dirigida cada vez más en dirección al "intelecto" (Lazzarato, 2006) o la "psique" (Han, 2018a) constituye uno de los nodos conceptuales más recientes de la ruptura con el modelo teórico de las sociedades disciplinarias de Foucault.

Lazzarato se inscribe en la propuesta teórica deleuziana de las sociedades de control. Sus planteos apuntan en dirección a polemizar con la idea de que en las dinámicas del poder postdisciplinario lo que se consolida es meramente una profundización y expansión de la biopolítica (Lazzarato, 2006: 9). Lazzarato conjuga el marco simondoniano de Deleuze con la apertura propuesta por Foucault respecto de la noción de seguridad, y para ello se vale de la recuperación de la obra de Tarde (1986). Lazzarato (2006) ubica el surgimiento de las técnicas y dispositivos del control a fines del 
s. XIX, momento en que Tarde da cuenta de cierto horizonte hacia cual comenzaba a apuntar algunas de las formas del poder ${ }^{9}$. Con público dicho autor se refiere a una determinada forma de configuración social que se caracteriza por su multidimensionalidad: un individuo en tanto público puede pertenecer a muchos públicos a la vez, mientras que no así como clase y masa (p. 93). En dicha configuración la "influencia de los espíritus" se caracteriza por constituir "acciones a distancia", en las que se desenvuelven "las técnicas del control, las tecnologías de acción a distancia de la imagen, del sonido y de los datos” (p. 99). Las acciones a distancia conllevan una subordinación del espacio al tiempo: "el público se constituye a través de su presencia en el tiempo" (p. 92), lo cual se contrapone a la centralidad espacial disciplinaria. Es posible reconocer que el concepto de espíritu -omitiendo todo el debate filosófico que amerita- mantiene mayor cercanía al concepto de psique o conciencia (en su reificación conceptual) que a la anatomía corporal. Aquí introduce Lazzarato la diferenciación entre una memoria de la vida, en lo que hace a sus características biológicas (nacimiento, enfermedad, muerte), de una memoria del espíritu, la cual requiere una nueva conceptualización.

La noopolítica, en tanto conjunto de técnicas del control, constituye una nueva modalidad del poder que toma como principal objeto/objetivo "la memoria y su conatus (la atención)". En relación a la composición morfológica de la categoría, el mismo Lazzarato destaca en el prefijo "noo" la referencia griega a "nous" (intelecto o espíritu en Platón y Aristóteles), como así también distingue que "es el nombre de un proveedor de acceso a Internet" (p. 105). Lo cual cobra sentido al reparar en el énfasis que distingue dicho autor en lo que respecta a la cibernética y los signos. De esta manera, la categoría de noopolítica articula conceptualmente lo que respecta al ciberespacio, los signos y el intelecto (o espíritu, bajo la tradición filosófica griega mencionada por Lazzarato).

Siguiendo a Tarde, la embestida del poder hacia a la memoria espiritual supone una avanzada en dirección a la sensibilidad, la vida, el tiempo y la duración que posibilita el crecimiento. Lazzarato (2006) lo expresa de la siguiente manera: "la captura, el control, y la regulación de la acción a distancia de espíritu a espíritu se hacen a través de la modulación de los flujos de deseos y de las creencias y de las fuerzas (la memoria y la atención) que los hacen circular en la cooperación entre cerebros" (p. 99).

En el centro de la cuestión encontramos un desplazamiento de la dimensión corporal a la psíquica y sígnica. Si bien "siempre es una cuestión de cuerpos", la dinámica del poder postdisciplinario tiende a avanzar fundamentalmente hacia a la "memoria espiritual" más que a la "memoria corporal". La noopolítica de Lazzarato se ejerce sobre el cerebro: "implicando en principio la atención", de manera que sea posible "controlar la memoria y su potencia virtual [en torno a aquello que puede ser y aun no es]” (p. 100).

La noopolitica no desplaza a la biopolítica. En la perspectiva de Lazzarato (2006): "el control se superpone a la disciplina" (p. 89). La noopolitica se configura por encima de la biopolítica y la anatomopolitica, tendiendo a articularse mutuamente con ambas, mientras las desplaza en su centralidad. Esta es una definición analítica muy acertada y útil de parte de dicho autor: las tecnologías del poder no simplemente se remplazan, sino que se solapan, articulan e imbrican mutuamente. La superposición de dinámicas noopoliticas y biopoliticas se manifiesta en: (a) la presencia de un moldeado de la memoria corporal por parte de las anatomopolíticas; (b) una gestión

${ }^{9}$ Con su propia genealogía lateral, pero en estrecha vinculación, frente al auge y preponderancia de los dispositivos y técnicas del biopoder. 
de la vida por parte de las biopolíticas; y (c) una modulación de la memoria y sus potencias virtuales por parte del conjunto de las técnicas del control (noopolíticas). Siguiendo a Lazzarato, la sumatoria de todo esto es lo que configura las actuales sociedades de control.

Son las "tecnologías del tiempo o de la memoria" aquellas que logran desarticular los "acontecimientos" (Foucault, 1987: 80), en tanto disrupciones imprevisibles frente al orden y la homologación social ${ }^{10}$, para modularlos en el torrente liso de la variedad equivalente: "una diversidad de opciones instituidas y creadas por el marketing, el medidor de audiencia, la publicidad, la información, etcétera" (Lazzarato, 2006: 165). Un ejemplo interesante que recupera Lazzarato son las tecnologías de video, las cuales detentan el potencial de ocupar una "duración" (tiempo) y captar la atención, dejando su huella en la "memoria" (p. 166). Lazzarato realiza su propuesta de la noopolítica "a falta de algo mejor" (p. 100), pero con aportes claves en dirección a la descripción de una nueva tecnología del poder y su imbricamiento con las 'viejas'.

Con algunas reflexiones que merecen nuestra atención, pero con menor rigurosidad metodológica, Han introduce su análisis sobre la Psicopolítica (2018a), en el marco de su propuesta de las sociedades del rendimiento, como conceptualización específica de las dinámicas del poder postdisciplinario. Desacierta Cerruti (2017) cuando inscribe la propuesta teórica de Han al interior de la propuesta deleuziana de las sociedades de control. Si bien recupera varias aristas de distintos teóricos del control ${ }^{11}$, Han (2012) establece una ruptura con la tradición deleuziana. Ubicándose en un posicionamiento teórico postmarxista, dicho autor considera que la noción de "control" sigue suponiendo una relación de dominación entre "unos" y "otros", una diferenciación entre "explotadores y explotados". En sus palabras: “el término «sociedad de control» (...) aún contiene demasiada negatividad" (p. 16). Sin embargo, es fructífera la propuesta de integrar algunos aportes de Han al interior del marco analítico postdisciplinario previo que nos brindan Foucault y Deleuze $^{12}$.

En contraposición a una imagen de la sociedad en la que es posible realizar una diferenciación entre explotadores y explotados, Han nos propone analizar a nuestras actuales sociedades neoliberales como aquéllas en las cuales se generaliza y configura una dinámica ordenada por la autoexplotación de los sujetos. En el punto de llegada de las rupturas con las dinámicas del poder disciplinario, encontramos otras dinámicas signadas por el agenciamiento de determinados imperativos por parte de los sujetos ${ }^{13}$. Dichos imperativos configuran distintas formas de violencia autodirigida, violencias "contra sí mismos". Butler (2001) diría que "la conciencia desventurada se toma a sí misma como su propio objeto de desprecio" (p. 57). Esto es posible

\footnotetext{
${ }^{10} \mathrm{El}$ acontecimiento en Foucault ocupa el lugar de aquello que constituye la acción imprevista y disruptiva frente a la preponderancia de lo equivalente. Dicha 'preponderancia de lo equivalente' incluso puede tomar la forma de eliminación de toda posibilidad de singularidad mediante la dinámica de los excesos: hipercomunicación, hiperinformación (Baudrillard, 2000; Han, 2017a). El acontecimiento foucaultiano constituye algo similar a ciertas reapropiaciones de la figura mítica y arquetípica griega del Kairós como un tipo de temporalidad cualitativamente distinta al Cronos (logía). Mientras el Cronos representa la temporalidad productiva, cuantitativa y racional, el tiempo del Kairós simboliza un tiempo de carácter profundo, trascendente y oportuno para el surgimiento de lo genuinamente distinto.

11 En algunos momentos inclusive realiza alusiones a la "sociedad del control digital" (Han, 2018a: 21).

12 En este campo de estudio, es necesario abandonar toda empresa analítica en la cual un autor solo pretenda brindar el marco teórico general para reflexionar en tornos a las dinámicas del poder de nuestras sociedades contemporáneas. Lo cual no quiere decir que descartemos todo elemento de dichos autores. Alimentar las conjunciones analíticas pareciera ser un escenario mucho más prometedor; estableciendo priorizaciones teóricas en base al sopesamiento critico de las herramientas, con los respectivos avances y estados de la cuestión que se vienen desarrollando en el registro teórico foucaultiano/postfoucaultiano en los últimos años

${ }^{13}$ Con Han vuelven a cobrar actualidad algunos de los planteos de Foucault en torno a las tecnologías del yo.
} 
bajo una nueva modalidad del poder: ya no centrada en las dimensiones corporales, sino en la psique; donde el individuo tiende a reproducir "por sí mismo el entramado de dominación que es interpretado por él como libertad" (Han, 2018a: 46). En esta línea de análisis, Han ha llegado a afirmar que los tiempos de la biopolítica y de los dispositivos inmunológicos (Esposito, 2005) quedaron atrás (Han, 2018a). Al parecer, los hechos recientes en torno a la pandemia del COVID-19, y sus respectivas consecuencias para las distintas sociedades del mundo, bastaron para invalidar dichas conjeturas (Han, 2020) ${ }^{14}$.

Con respecto a las diferencias con las técnicas y dispositivos del poder disciplinario, Han (2018a) afirma que son muy burdas "para penetrar en las capas profundas de la psique con sus anhelos ocultos, sus necesidades y su deseo, y acabar apoderándose de ellas" (p. 37). Las dinámicas del poder disciplinario se caracterizan por un condicionar desde la negatividad, desde un 'deber'. La delimitación de un deber -el “tú debes” que Han recupera de Nietzsche (2009: 25)que pretende obligar al sujeto, pierde efectividad frente a la capacidad psicopolitica de un poder permisivo/persuasivo: el cual se apoya ampliamente en "el verbo modal positivo poder" (Han, 2012: 16). La dominación psicopolítica busca el "acceso al pensamiento" y al mundo de las "necesidades internas", allí donde no penetra el poder biopolítico ya que es una política centrada en la corporalidad. En cambio, los dispositivos y técnicas del poder psicopolitico configuran un "poder permisivo" (Han, 2018a: 27), el cual pretende seducir y penetrar en el pensamiento (e inclusive hasta en lo más inconsciente) para que el sujeto se someta autónomamente a los requerimientos de la sociedad neoliberal. Dicho poder "en lugar de hacer a los hombres sumisos intenta hacerlos dependientes" (p. 29).

Este desplazamiento de un poder centrado fundamentalmente en la construcción de mandatos normativos a otro proveedor de 'libertades', según Han (2018a) no se encuentra escindido de la tendencia del capital hacia el aumento de la productividad y la mayor concentración. De hecho, la coacción del 'deber' tiene un límite al no involucrar el deseo del sujeto, al afirmarse más en la negatividad de la obligatoriedad que en la positividad de la permisividad, mientras que el "poder hacer" (p. 12) no tiene límites. Para este autor, la fórmula paradójica de nuestro tiempo es que la experiencia de libertad deviene en la más plena coacción: "el sujeto del rendimiento, que se pretende libre, es en realidad un esclavo. Es un esclavo absoluto, en la medida en que sin amo alguno se explota a sí mismo de forma voluntaria” (Ibíd.).

El desarrollo y generalización en la sociedad de las TIC's, constituye el firmamento desde donde las dinámicas del poder psicopolítico pueden desarrollarse. Los planteos de Han son factibles de ser analizados en el marco de las descripciones realizadas por Pasquinelli (2011) sobre la sociedad de los metadatos y la definición de gubernamentalidad algoritmica de Rouvroy y Berns (2016). En la medida en que el Big Data logra hacer legibles y convertir en información "aquellos deseos de los que no somos conscientes de forma expresa", cabe la posibilidad de que estemos frente a "una psicopolítica que interviniera hasta en lo más profundo de nuestra psique y la explotara" (Han, 2018a: 96). En la propuesta de Han, la psicopolitica constituye una avanzada del poder hacia el inconsciente, pero no sólo en términos individuales. Al predecir y modular patrones de comportamientos colectivos, "se podría acceder al inconsciente colectivo" (p. 98) ${ }^{15}$.

\footnotetext{
14 Tras el horizonte de la salud de los cuerpos, la corporalidad vuelve al centro de escena tras un breve periodo de predominio exclusivo de las tecnologías del poder psicopolíticas/noopolíticas. De este modo, la biopolítica se hace presente con plena vigencia y bajo nuevas modalidades.

${ }^{15} \mathrm{El}$ registro ensayístico y filosófico de Han, si bien propone un conjunto de ideas interesantes en lo que respecta a las nuevas dinámicas del poder, carece de un conjunto de precisiones conceptuales. Han no precisa de dónde retoma
} 
Han (2017a) resalta la tendencia hacia una constante transparentización de la sociedad. De la mano del panóptico digital, dónde "exposición es explotación" (p. 30), todo tiende a exteriorizarse, a comunicarse: "el imperativo de la transparencia hace sospechoso todo lo que no se somete la visibilidad" (p. 31). Esto cimienta las condiciones de posibilidad para hacer realidad la utopía positivista de la eliminación de la negatividad o La expulsión de lo distinto (Han, 2017c). La vorágine de la hipercomunicación y la hiperinformación invade todos los intersticios de lo social, eliminando lo alternativo (el acontecimiento en Foucault) y tendiendo a consolidar el "infierno de lo igual" (Han, 2017a: 12).

Han pone énfasis en el tipo de vínculo que establecen los sujetos contemporáneos con los demás y consigo mismos, a partir de la preponderancia de la mediación digital propia del ciberespacio. Neuroticismo y narcisismo son los pilares fundamentales de dicha dinámica. A partir de la lógica algorítmica del Big Data, las plataformas digitales detentan la capacidad de ordenar el contenido que cada sujeto/usuario va a encontrar allí en función de sus inclinaciones, intereses, opiniones y valoraciones previas. La dinámica digital tiende a devolver una imagen del mundo con capacidad de ajustarse permanentemente a cada subjetividad. De esta manera, se va configurando un círculo de espejos, donde el sujeto no deja de encontrarse a sí mismo en la imagen del mundo que recibe, en dirección a explotar y armonizar la subjetividad al "infierno de lo igual". Por ello afirma Han (2012) que "el sujeto narcisista-depresivo está agotado y fatigado de sí mismo" (p. 15).

Aquella sentencia de Deleuze (1991) que afirma que "en las sociedades de control nunca se termina nada" (p. 3), es reactualizada por Han (2012): el sujeto del rendimiento va corriendo incesantemente tras un 'éxito' siempre inconcluso, desarrollando una "depresión del éxito" (p. 6). El sujeto "depresivo-narcisista" no es capaz de concluir nada, "y sin conclusión todo se derrama y se esfuma” (p. 17). Al constituirse una distancia tan grande entre el 'yo real' y el 'yo ideal', surge la autoagresividad que se manifiesta en el aumento contemporáneo de enfermedades psíquicas como el burnout (agotamiento) y la depresión (Han, 2017b: 62).

En el plano vincular y afectivo, Han (2018b) describe cómo la eliminación de las distancias que pregonan las RR.SS. cercenan toda posibilidad de profundidad y trascendencia en la experiencia afectiva. La misma tiende a buscarse despojada de todo dolor (negatividad), amortiguada de todo elemento imprevisto o indefinido (acontecimiento) y lo más ajustadamente posible a las funcionalidades del proyecto biográfico individual (narcisista) (p. 18). En fin, encontramos en Han también un análisis sobre la reificación del amor, donde la generalización del narcisismo en nuestras sociedades tiende a obturar toda posibilidad de vínculo con el otro/a/e como una alteridad.

A modo de cierre, procederé a desarrollar brevemente una propuesta de articulación analítica entre ambas propuestas teóricas expuestas.

la noción de psique, ni tampoco la de inconsciente o inconsciente colectivo. Siguiendo algunas de sus producciones (2012, 2017a, 2017b, 2017c, 2018a y 2018b), es posible deducir que se inscribe en la concepción freudiana de dichos términos. Sin embargo, la categoría de inconsciente colectivo no remite al psicoanálisis freudiano, más bien forma parte de la psicología analítica junguiana (Jung, 2015). Partiendo de una determinada interpretación de la concepción freudiana del inconsciente, Han (2017b) afirma que el mismo ha dejado de existir: "si el inconsciente está ligado necesariamente a la negación de la negación y la represión, entonces el sujeto de rendimiento de la Modernidad tardía ya no tiene inconsciente. Estamos ante un yo postfreudiano" (p. 46). 


\section{Las tecnologías del poder psicopolíticas/noopolíticas}

A la hora de describir el surgimiento de una nueva tecnología del poder, es posible identificar que el marco analítico que propone Lazzarato (2006) es más útil que el que nos ofrece Han (2018a). En la sistematización que desarrolla Lazzarato: (1) la nueva tecnología del poder no simplemente reemplaza a las anteriores, sino que se superponen e imbrican mutuamente; (2) se recuperan e interrelacionan los aportes de Tarde y Simondon a la hora de analizar las formas en que estas nuevas tecnologías del poder tienden a desenvolverse; (3) no se considera que esta nueva modalidad del poder arroje como resultado una eliminación de las diferencias entre explotadores y explotados; (4) por último, dicha propuesta cuenta mayores precisiones metodológicas y conceptuales, frente al estilo predominantemente ensayístico de Han.

La complejización de las dinámicas del poder en nuestras sociedades neoliberales de sobremodernidad, no nos puede llevar a creer que se extermina la diferencia entre explotadores y explotados, como ocurre en Han. Dicho autor pareciera querer expresar que la humanidad camina inevitablemente hacia una fatalidad distópica, o un "crimen perfecto" en palabras de Alemán (2018). Sostener esto sólo es posible a partir de un aislamiento de las dimensiones de la realidad, o un sobredimensionamiento de algunas de ellas frente a una nulidad analítica en la consideración de otras. Por dar un ejemplo clave: toda la obra de Han se encuentra ajena a la dimensión geopolítica. No encontramos en dicho autor ningún tipo de mención en lo que respecta a la disputa geopolítica y geoestratégica a nivel mundial ${ }^{16}$. Han supone una hegemonía absoluta del capital, sin distinciones ni matices.

De Han (2018a) sí destacamos un conjunto de análisis sumamente interesantes y reveladores sobre ciertas dinámicas recientes en que se expresa el poder. Cuando Deleuze $(1987,1991)$ propuso la categoría de sociedades de control, reconoció recuperar la centralidad de la idea de control del novelista William Burroughs (1989), quien en su novela El almuerzo desnudo escribió: "a partir de cierta frecuencia, la necesidad no conoce límite ni control alguno" (p. 9). Esta es una de las vetas que recupera Han: analizar las formas en que la psicopolitica logra construir y explotar necesidades/dependencias. Allí, la seducción cumple un papel clave en los énfasis de esta nueva tecnología del poder. Como dijera también Foucault (2007), hablamos de un poder que "se inscribe en el comportamiento de los sujetos actuantes: incita, induce, seduce, facilita o dificulta" (p. 15).

En el horizonte de un poder en el que tiende a primar -como nunca antes- la importancia del desarrollo y despliegue de las TIC's, podemos afirmar que tuvo lugar una revolución de las tecnologías del poder, la cual dio lugar a las tecnologías de la psicopolítica/noopolítica. El respectivo apropiamiento de los mandatos de rendimiento, transparencia, narcisismo y positividad configuran los principales pilares de un conjunto de dinámicas que apuntan, como nunca antes, a la equivalencia entre dominación y libertad ${ }^{17}$.

16 Particularmente, en relación a la dimensión geopolítica, volvemos a destacar la importancia de seguir contribuyendo a la conjunción teórica de las teorías del poder foucaultianas/postfoucaultianas y lo que denominamos perspectivas situadas (perspectivas decoloniales y teoría de la dependencia, fundamentalmente).

17 La tendencia descrita por Gramsci, en relación a que las formas de la hegemonía capitalista tienden a apoyarse cada vez menos de la coacción física y cada más en el consenso, posiblemente encuentran su máxima cristalización en las técnicas y dispositivos de la psicopolítica/ noopolítica. 
La conjunción de Lazzarato y Han además nos permite integrar los registros del ciberespacio, los signos, la memoria, con aquellos que atañen a una perspectiva centrada en la psique, el inconsciente y las políticas del deseo. Dicho espectro involucra: las TIC's; la cuestión sígnica que trae aparejada los procesos de modulación propia de las dinámicas del control deleuziano ${ }^{18}$; y un conjunto de políticas del tiempo y de la memoria. Estas últimas también constituyen políticas a distancia que dejan huella en la memoria -según Tarde, de la mano de Lazzarato- las cuales salen al encuentro del registro de estudio de las políticas de la psique (psicopolítica), fundamentalmente del inconsciente $\mathrm{y}$ en dichos registros los estudios en torno a los binomios poder-deseo ${ }^{19}$, necesidad-dependencia.

Las tecnologías del poder psicopolíticas/noopolíticas requieren ser abordadas en diálogo constante con: los desarrollos de Pasquinelli $(2010,2011)$ sobre las sociedades de los metadatos; la propuesta de Rouvroy y Berns (2016) al respecto de las dinámicas propias de la gubernamentalidad algoritmica; y los aportes de Kotler y Armstrong (2013) sobre el marketing dirigido. A su vez, dichas herramientas requerirán ser contextualizadas en el marco de la "revolución digital" (Ceceña, 1996; Martins, 2011), el "capitalismo de plataformas" (Srnicek, 2018) o "cognitivo" (Rullani, 2004; Zukerfeld, 2006) y lo que el máximo exponente del Foro Económico Mundial de Davos ha dado en llamar la "Cuarta Revolución Industrial" (Schwab, 2016).

Entrelazando brevemente algunos de los aportes expuestos, podemos decir que las técnicas y dispositivos del poder postdisciplinario no sólo logran poner a unos individuos contra otros, sino que su principal astucia consiste en poner a los individuos contra ellos mismos. Las tecnologías del poder psicopolíticas/noopolíticas, despliegan su capacidad de fragmentación subjetiva, de “corrosión del carácter" (Sennett, 2007) o de "desubjetivación” (Agamben, 2014), gracias a su capacidad de intervenir en elementos sumamente específicos de procesos tanto inter como intra individuales; técnicas y dispositivos del poder que apuntan, como nunca antes, hacia la dividuación (Simondon, 2014) de la mano de los dispositivos de la gubernamentalidad algorítmica (Rouvroy y Berns, 2016) fundamentalmente.

Desde esta perspectiva es genuinamente fructífera la integración analítica de Lazzarato y Han. Como afirmamos, su conjunción puede ser el núcleo conceptual de una caja de herramientas mixta, incluyendo también los aportes de autores ya consolidados en este espectro postdisciplinario como Agamben (2010, 2014, 2015), Sibilia (2005) y Baudrillard (1978, 1999), entre otros. Además de ello, es de suma utilidad su formulación en tanto será necesario analizar los nuevos modos de articulación e imbricamiento mutuo entre psicopoder/noopoder y biopoder ${ }^{20}$.

Quedará en mano de nuestras generaciones la necesidad de aportar y fortalecer las conjunciones analíticas de las cuales nos serviremos para estos tiempos. Su encuentro será en la práctica: en la necesidad de desentrañar las transformaciones del poder en curso y realizar aportes para la superación de la actual crisis civilizatoria.

\footnotetext{
18 De la mano de Deleuze, contamos con Simondon y su potencial epistemológico a la hora de analizar las dinámicas del poder contemporáneas. En dicha dirección, Stiegler (2016) formula unos primeros pasos claves.

19 Allí Baudrillard $(1978,1999)$ constituye una de las fuentes claves de Han.

20 A modo de ejemplo, podemos nombrar la presentación de Elon Musk -propietario de Tesla, Inc. y de la compañía espacial SpaceX- del nuevo chip cerebral que "pretende curar enfermedades neurológicas". Ver: https://www.elmundo.es/ciencia-y-salud/ciencia/2020/08/31/5f4cc1f5fdddffa9b38b464f.html
} 


\section{Referencias}

Agamben, G. (2010). El poder soberano y la nuda vida. Valencia: Pre-Textos.

Agamben, G. (2014). ¿Qué es un dispositivo? Buenos Aires: Adriana Hidalgo editora.

Agamben, G. (2015). Del estado de derecho al estado de seguridad. Diario Le Monde, 23 de diciembre de 2015. En español, recuperado de: http:/ /artilleriainmanente.blogspot.com.ar/2015/12/giorgio-agambendelestado-dederecho.html

Alemán, J. (2018). Capitalismo. Crimen perfecto o emancipación. Barcelona: Ned Ediciones.

Auge, M. (2000). Los "no lugares" espacios del anonimato. Barcelona: Editorial Gedisa.

Barrios, M-A. (2019). Cibergeopolítica: un análisis estratégico desde Nuestra América. Revista América Latina en movimiento. Disponible en: https://www.alainet.org/es/articulo/200598

Baudrillard, J. (1978). Cultura y simulacro. Barcelona: Editorial Kairós.

Baudrillard, J. (1999). Olvidar a Foucault. Valencia: Pre-textos.

Baudrillard, J. (2000). La ilusión vital. Buenos Aires: Siglo XXI.

Beck, U. (1998). La sociedad del riesgo. Hacia una nueva modernidad. Buenos Aires: Paidós.

Burroughs, W. (1989). El almuerzo desnudo. Barcelona: Editorial Anagrama.

Butler, J. (2001). Mecanismos psiquicos del poder. Teorías sobre la sujeción. Madrid: Ediciones Cátedra.

Castells, M. (2000). La era de la información: Economia, sociedad y cultura. Volumen I. La sociedad de la información. Versión castellana de Carmen Martínez Gimeno y Jesús Alborés.

Castro-Gómez, S. (2007). Michel Foucault y la colonialidad del poder. Tabula Rasa 6: 153-172.

Castro-Gómez, S. (2010). Michel Foucault, colonialismo y geopolítica, en I. Rodríguez y J.Martínez (ed.). Estudios transatlánticos postcoloniales. 1: 271-292. Madrid: Anthropos

Cerruti, P. (2017). De la biopolítica a la psicopolítica: comunicación, poder y subjetividad a partir de Michael Foucault. CONICET-CIECS. Revista Astrolabio. N$^{\circ} 19$.

Couldry, N. y Mejias, U. (2019) Los costos de conexión. California: Universidad de Standford

Cruz Ortiz de Landázuri, Manuel (2017). De la biopolítica a la psicopolítica en el pensamiento social de ByungChul Han. Athenea Digital, 17(1), 187-203. http://dx.doi.org/10.5565/rev/athenea.1782

Deleuze, G. (1987). ¿Qué es el acto de creación? Buenos Aires: Proyecto Trama. Disponible en: https://gep21.files.wordpress.com/2010/02/deleuze-c2bfque-es-el-acto-de-creacion.pdf

Deleuze, G. (1991). Posdata sobre las sociedades de control, en Christian Ferrer (Comp.) Montevideo: Ediciones Nordan. Disponible http://www.fundacion.uocra.org/documentos/recursos/articulos/Posdata-sobre-lassociedades-de-control.pdf.

Deleuze, G. (2008) Foucault. Buenos Aires: Paidós.

Deleuze, G. y Guattari, F. (1985). El Anti Edipo. México: Paidós.

Diaz, E. (2000) Posmodernidad. Buenos Aires: Biblos.

Esposito, R. (2006). Bíos. Biopolítica y filosofía. Buenos Aires: Amorrortu editores.

Estrada-Mesa, D. A. y Cardona-Arias, J. A. (2018). La medicina en la obra de Michel Foucault: Meta-síntesis. Revista Civilizar. 18(34), 223-236.

Foucault, M. (1968). Las palabras y las cosas. Una arqueología de las ciencias bumanas. Buenos Aires: Siglo XXI.

Foucault, M. (1977). Historia de la medicalización. Educación, medicina y salud 10(2), 152-169. Rio de Janeiro. 
Foucault, M. (1979a). Microfísica del poder. Madrid: Las Ediciones de La Piqueta.

Foucault, M. (1979b). Saber y verdad. Madrid: La Piqueta.

Foucault, M. (1987). De la subversión del conocimiento. Frankfurt del Meno: Fischer.

Foucault, M. (1998). Historia de la sexualidad I. La voluntad de saber. Madrid: Siglo XXI.

Foucault, M. (1999). Estética, ética y hermenéutica. Buenos Aires: Paidós.

Foucault, M. (2000). Un diálogo sobre el poder. Madrid: Alianza.

Foucault, M. (2002a). Vigilary castigar. Buenos Aires: Siglo XXI.

Foucault, M. (2002b) Las Redes del Poder. Recuperado de: http://www.lite.fae.unicamp. $\mathrm{br} /$ papet/2002/fe190d/texto05.htm

Foucault, M. (2006). Seguridad, territorio, población. Curso en el Collège de France: 1977-1978. Buenos Aires: Fondo de Cultura Económica.

Foucault, M. (2007). Nacimiento de la biopolítica. Buenos Aires: Fondo de Cultura Económica.

Foucault, M. (2008). Tecnologías del yo y otros textos afines. Buenos Aires: Paidós.

Foucault, M. (2011). La verdady las formas jurídicas. Barcelona: Editorial Gedisa.

Galcerán, M. (2019). Marxismo y estudios poscoloniales: críticas y contracríticas. Revista Viento Sur $\mathrm{n}^{\circ}$ 165. Disponible en: https://vientosur.info/spip.php?article15061

Galparsoro, J-I. (2017). Big Data y Psicopolítica. Vía de escape: de la vida calculable a la vida como obra de arte. ILEMATA. Año 9, N²1, 25-43.

Gendler, M. A. (2017). Sociedades de Control: lecturas, diálogos y (algunas) actualizaciones. Buenos Aires: Hipertextos, 5(8). Disponible en: http://revistahipertextos.org/wpcontent/uploads/2015/12/Gendler.pdf

Gramsci, A. (1990). Notas sobre Maquiavelo, sobre la politica y sobre el Estado moderno. Buenos Aires: Nueva visión.

Grosfoguel, R. (2012). El concepto de "racismo" en Michel Foucault y Frantz Fanon: ¿teorizar desde la zona del ser o desde la zona del no-ser? Tabula Rasa 16 (2012), 79-102.

Han, B-C. (2012). La sociedad del cansancio. Barcelona: Pensamiento Herder.

Han, B-C. (2017a). La sociedad de la transparencia. Buenos Aires: Pensamiento Herder.

Han, B-C. (2017b). Topología de la violencia. Buenos Aires: Pensamiento Herder.

Han, B-C. (2017c). La expulsión de lo distinto. Buenos Aires: Pensamiento Herder.

Han, B-C. (2018a). Psicopolítica. Buenos Aires: Pensamiento Herder.

Han, B-C. (2018b). La agonía del Eros. Buenos Aires: Pensamiento Herder.

Han, B-C. (2020). La emergencia viral y el mundo de mañana. Byung-Chul Han, el filósofo surcoreano que piensa desde Berlín. Diario El País. 22 de marzo del 2020.

Jung, C-G. (2015). Arquetipos e inconsciente colectivo. Buenos Aires: Paidós

Lazzarato, M. (2006). Políticas del acontecimiento. Buenos Aires: Editorial Tinta Limón.

Lazzarato, M. (2001). Trabajo inmaterial y subjetividad. En Lazzarato, Maurizio y Antonio Negri. Trabajo inmaterial. Formas de vida y producción de subjetividad, 11-18. Río de Janeiro, DP\&A Editora.

Mallamali, M-G. (2017). El poder psicopolítico en las sociedades postdisciplinarias del homo digitalis. Apuntes sobre el pensamiento de Byung-Chul Han. Revista Latina de Sociología (RELASO) 7(1) (2017) pp. 74-94. ISSN-e 2253-6469.

Masuda, Y. (1984). La sociedad informatizada como sociedad post-industrial. Madrid: Fundesco-Tecnos.

Muir, L. (2012). ¿Espacio de control? Representaciones cinematográficas del espacio de vigilancia entre disciplina y control. Kingston. Universidad de Queen.

Nietzsche, F. (2009). Así habló Zaratustra. Buenos Aires: Ediciones Libertador. 
Pasquinelli, M. (2011). Capitalismo de la máquina y plusvalía de la red: notas sobre la economía política de la máquina de Turing. Disponible: http://www.uninomade.org/capitalismomacchinico/

Preciado, P.B. (2020). Aprendiendo del virus. Diario El País. 28 de marzo del 2020. Disponible en: https://elpais.com/elpais/2020/03/27/opinion/1585316952_026489.html

Prueger, J. (2020). Las teorías del poder postdisciplinario (Tesis de grado). Presentada en Universidad Nacional de La Plata. Facultad de Humanidades y Ciencias de la Educación para optar al grado de Licenciado en Sociología.

Restrepo, E. (2004). Teorías contemporáneas de la etnicidad: Stuart Hall y Michel Foucault. Popayán: Editorial Universidad del Cauca.

Rodriguez, P. (2008). ¿Qué son las sociedades de control? Sociedad, 27. Buenos Aires: Prometeo/Facultad de Ciencias Sociales. Disponible en: http://www.sociales.uba.ar/wpcontent/uploads/21.-Qu\%C3\%A9-son-las-sociedades-de-control.pdf

Rodriguez, P. (2010). Episteme posmoderna y sociedades de control. Deleuze, heredero de Foucault. Revista Márgenes. 5 (7). Belém: Universidade Federal do Pará.

Rodriguez, P. (2015a). 10 preguntas a una postdata misteriosa. Sobre las sociedades de control de Gilles Deleuze. En Libro de Actas de las VI Jornadas de Debates Actuales. Disponible en: https://www.academia.edu/33718989/Diez_preguntas_a_una_posdata_misteriosa._Sobre_1 as_sociedades_de_control_de_Gilles_Deleuze

Rodriguez, P. (2015b). Espectáculo de lo Dividual: Tecnologías del yo y vigilancia distribuida en las redes sociales. Revista ECOPOS, 18 (2). Tecnopolíticas e Vigilancia. Recuperado de https://revistas.ufrj.br/index.php/eco_pos/article/view/2680/2249

Rodriguez, P. (2019). Las palabras en las cosas. Buenos Aires: Cactus.

Rouvroy, A. y Berns, T. (2016). Gubernamentalidad algorítmica y perspectivas de emancipación: ¿lo dispar como condición de individualización por relación? Revista ECOPOS, 18 (2). Tecnopolíticas e Vigilancia pp. 36-56, Recuperado de: https://revistas.ufrj.br/index.php/eco_pos/article/view/2662/2251

Rullani, E. (2004). El capitalismo cognitivo: ¿un déjà-vu? En VV. AA. (2004). Capitalismo cognitivo, propiedad intelectual y creación colectiva. Madrid: Traficante de sueños.

Said, E-W. (1990). Orientalismo. Buenos Aires: Editorial Debate.

Said, E-W. (1996). Cultura e imperialismo. Buenos Aires: Editorial Debate.

Schwab, K. (2016). La cuarta revolución industrial. World Economic Forum: Debate.

Sennet, R. (2007). La cultura del nuevo capitalismo. Barcelona: Editorial Anagrama.

Sibilia, P. (2005). El hombre postorganico. Cuerpo, subjetividad y tecnologias digitales. Buenos Aires: Fondo de Cultura Económica.

Simondon, G. (2014). La individuación a la luz de las nociones de forma y de información. Buenos Aires: Cactus.

Srnicek, N. (2018). Capitalismo de plataformas. Buenos Aires: Caja Negra.

Stiegler, B. (2016). Gilbert Simondon: repercusión y perspectivas. Demarcaciones. Número 4. Mayo 2016.

Tarde, G. (1902). La Psychologie économique. Paris: Alcan.

Tarde, G. (1986). La opinión y la multitud. Madrid: Taurus.

Velásquez, L-A. (2012). Noopolítica, el gobierno de la conducta de los demás: un acercamiento al pensamiento de Mauricio Lazzarato. Revista Bogota (Colombia). 7 (2). julio-diciembre. 
Walsh, C. (2005). Interculturalidad, colonialidad y educación. Seminario Internacional (Etno) educación, multiculturalismo e interculturalidad. Bogotá. Del 1 al 4 de noviembre.

Zukerfeld, M. (2006). Bienes Informacionales y Capitalismo Cognitivo: Conocimiento, Información y Acceso en el siglo XXI. Razón y Palabra, 1-14. 